\title{
Automated and machine learning approaches in diagnostic hearing assessment: a scoping review
}

Authors: Leontien Pragt ${ }^{1}$, Jan-Willem A. Wasmann ${ }^{1 *}$, Robert H. Eikelboom ${ }^{2,3,4}$, De Wet Swanepoel ${ }^{2,3,4}$

\author{
Author Affiliations \\ ${ }^{1}$ Department of Otorhinolaryngology, Donders Institute for Brain, Cognition and Behaviour, Radboud university \\ medical centre Nijmegen, the Netherlands; \\ ${ }^{2}$ Ear Science Institute Australia, Subiaco, Western Australia, Australia;
}

${ }^{3}$ Ear Sciences Centre, Medical School, The University of Western Australia, Nedlands, Australia;

${ }^{4}$ Department of Speech-Language Pathology and Audiology, University of Pretoria, South Africa;

\section{Please send correspondence to:}

Jan-Willem Wasmann

Philips van Leydenlaan 15

P.O. Box 9101

6500 HB Nijmegen

The Netherlands

E-mail: Jan-Willem.Wasmann@radboudumc.nl

Phone: +31 (0)24- 3610426 


\begin{abstract}
Hearing loss affects one in five people worldwide and is estimated to affect one in four by 2050. Treatment relies on accurate diagnosis of hearing loss, but this first step is out of reach for more than $80 \%$ of those affected. Increasingly automated digital approaches are being developed for self-administered hearing assessment without professionals' direct involvement. This scoping review provides an overview of automated approaches, based on 56 reports from 2012 until June 2021, adding to the 29 published prior to 2012. Twentyseven automated approaches were identified. An increasing number of approaches report similar accuracy as manual hearing assessments. Machine learning approaches are more efficient and personal digital devices make assessments more affordable and accessible. Validity can be enhanced by quality surveillance including noise monitoring and detecting inconclusive results. Employed within identified limitations, automated hearing assessments can support task-shifting, self-care, and clinical care pathways.
\end{abstract}

\title{
Introduction
}

Hearing loss affects 1.5 billion persons globally and is expected to increase by another billion by $2050 .{ }^{1,2}$ Hearing testing is the first step towards appropriate and timely treatment. Unfortunately, most affected persons are unable to access hearing assessments with less than one hearing health professional for every million people in regions such as Africa. ${ }^{2,3}$ Increasingly automated approaches (all aspects of the method associated with automated audiometry), including machine learning, are being developed and made available that provide selfadministered hearing assessment without necessitating professionals' direct involvement, enabling health care pathways with the potential to increase accessibility, efficiency and scalability within a network of distributed expertise. ${ }^{4}$ Recent examples of automated hearing assessments include clinical- and consumer-grade applications. ${ }^{5}$ General global health trends suggest that increased availability of diagnostic tools could lower healthcare costs while improving quality of life. ${ }^{6}$ For example, in Parkinson's disease, remote care based on wearables provides ecologically valid methods for monitoring and evaluating symptoms. ${ }^{7,8}$ In tuberculosis screening in low-resource settings, automated diagnosis can increase sensitivity of identifying persons at risk while reducing cost. $^{9}$

Timely detection and treatment of hearing loss is essential to enable optimal outcomes and quality of life across the life course. ${ }^{2}$ Untreated hearing loss restricts language development and educational potential in children and 
is associated with more rapid cognitive decline in adults. ${ }^{10}$ It may lead to social isolation, lower socioeconomic status, increased social disparities and decreased health, resulting in lower quality of life at the individual level and substantial costs at the community level. ${ }^{11,12}$ Importantly, treating hearing loss in mid-life has been identified as the largest potentially modifiable risk factor for developing dementia in later life. ${ }^{13}$ The global annual cost of untreated hearing loss is $\$ 980$ million. ${ }^{11}$ Global health investment models indicate a significant return of investment both in hearing diagnosis and treatment. ${ }^{2}$ The capacity of the entire clinical pathway should be increased since a bottleneck looms if the accessibility of diagnosis is increased faster than the availability of affordable treatment and rehabilitation.

Automated self-test options are important for detecting and diagnosing hearing loss to direct timely and appropriate treatments. The overwhelming majority of treatments are for permanent age-related and noiseinduced hearing loss, but a significant portion of the population requires medical treatment for hearing loss. ${ }^{1}$ The onset of COVID-19 has further emphasised the importance of self-test approaches. ${ }^{14,15}$ Automation is a powerful enabler for alternative diagnostic pathways that can include home-based testing, low-touch service models outside traditional clinic settings, and decentralised community-based models that rely on task-shifting to minimally trained facilitators. ${ }^{16}$

Automation in hearing assessment is not a new concept and dates back more than seven decades. ${ }^{17}$ In recent years, it has resurged with the convergence of digital and machine learning approaches. The primary tool for hearing assessment is pure-tone audiometry which describes the degree of hearing loss relative to normal hearing persons expressed in decibels Hearing Level (dB HL) across specific frequencies (125 - $8000 \mathrm{~Hz})$. Puretone audiometry can also differentiate the type of hearing loss, i.e. sensorineural or conductive, when bone conduction and air conduction transducers are used. Machine learning-based threshold seeking approaches, known as Bayesian active learning, have demonstrated their potential to optimise efficiency and increase automated hearing assessments' precision. ${ }^{18}$ Increased precision comes naturally since Bayesian active learning provides an estimate of hearing threshold as a continuous function of frequency. ${ }^{19,20}$

In 2012, a systematic review that included 29 reports on automated audiometry showed that automated procedures have comparable accuracy as manual procedures when performing air conduction audiometry. However, few validated automated procedures that included automated bone conduction audiometry had been 
reported, machine learning based audiometry approaches were not reported yet, and approaches were rarely validated in children or hard to test populations. ${ }^{21}$ Since 2012, there has been significant work and innovation in this area, which calls for an update and extension of the previous review. This scoping review aims to provide the current status of automation and machine learning approaches in hearing assessment using pure-tone audiometry with potential indicators of accuracy, reliability and efficiency of these approaches.

\section{Method}

We conducted a systematic scoping review of peer-reviewed literature on automated and machine learning approaches to pure-tone threshold audiometry and their accuracy, reliability, and efficiency. This review followed the methodological framework outlined in Arksey \& O'Malley. ${ }^{22}$

\section{Identifying potentially relevant records}

A search across the electronic databases from PubMed, IEEE, and Web of Sciences was conducted to identify relevant reports from peer-reviewed literature. Complementary and redundant search terms were applied to ensure thorough coverage and cross-checking of search findings. In the PubMed database, medical subject headings and relevant keywords were collected to determine all records relating to the study aim. The following synonyms of, and closely related terms to, automated audiometry were used: automatic audiometry, selfadministered audiometry, self-assessment audiometry, and user-operated audiometry. The complete set of terms and applied search strategy are provided in the supplemental materials, Table 1. The IEEE database is engineering-oriented, and only relevant keywords based on audiometry were used since it was assumed that any result in audiometry would be highly associated with automated audiometry. The Web of Science database is known to index the PubMed and IEEE databases and was explored using similar search terms as for the PubMed search. After preliminary explorations to identify appropriate keywords, we conducted a search on 8 July 2020 and updated it on 12 January 2021 and 6 July 2021. The search includes all reports that meet the inclusion criteria published from 1 January 2012 until 30 June 2021. The start date was chosen as we regard this scoping review as an extension and generalisation of a previous (systematic) review by Mahomed et al.,. ${ }^{21}$ which included studies up to 20 July 2012.

Selecting relevant records 
There were three inclusion criteria the reports had to meet; (i) the report had to be about automated or machine learning, pure-tone frequency-specific threshold audiometry; (ii) written in English; (iii) the automated threshold audiometry had to be compared against the gold standard or reasonable standard. The gold standard is defined as manual audiometry in a sound booth according to ISO standards. The automated audiometry also needed to be performed inside a sound booth, and results needed to be compared to the gold standard. A reasonable standard for validation was defined as either a within-subject comparison between the gold standard and automated audiometry in an unconventional setting (for example, a quiet room), or a within-subject comparison between a validated automated audiometry approach and an experimental approach of audiometry in the same unconventional setting.

We excluded reports on screening audiometry (e.g. gave pass/refer as an outcome) rather than threshold audiometry, review papers and studies reporting approaches that were not compared to the gold or reasonable reference standard.

The first phase of the screening was based on title. If the title indicated that content was within the scope of the research question (i.e. automated or machine learning approaches in diagnostic hearing assessment), the report was included into the second screening phase. In the second phase, the remaining reports' abstracts were assessed using the inclusion and exclusion criteria stated above.

Two authors (LP and JWW) conducted the abstract screening. They were blinded from each other to avoid confirmation bias. After the screening, the authors discussed any disagreements to reach an agreement. When in doubt, the report was admitted to the third, full-text review phase. In this phase, all remaining reports were reviewed in full to determine if the inclusion criteria were met. As can be seen in the PRIMSA flow diagram, Figure 1, the resulting selection of reports was complemented by additional reports. After some reports were clustered as having identical approaches (explained under the heading "Collating approaches, summarising, and reporting the results"), additional reports were added to avoid missing validation data of these clustered approaches. These reports were published before the inclusion date criteria (from before 1 January 2012) or did not appear in the search and were added based on the reference lists of the already included reports.

--- place figure 1 around here ---

Extracting data items 
A template for grading the reports was agreed upon by all authors (supplementary materials, Table 2). Two authors (LP and JWW) independently extracted the information directly relevant to the scoping review question. In cases of disagreement, a consensus was reached after discussion between these two authors. The compulsory data fields were: test frequency and intensity range; response method; test equipment including the type of transducers; calibration; hardware; test quality control; accuracy; validation; and test population. Where available, accuracy was expressed in decibel (dB) using the overall root-mean-square-deviation (RMSD) between the automated approach and the gold (or reasonable) standard ore between test and retest. Based on the work by Margolis et al. ${ }^{23}$ and the minimum acceptable accuracy recommended by clinical guidelines, ${ }^{24}$ a RMSD of $6 \mathrm{~dB}$ and $10 \mathrm{~dB}$ was chosen as criteria for desired and minimal accuracy, respectively. The data collected from the reports provided key information about each report's scope and details, enabling the authors to assess commonalities between the approaches.

\section{Collating approaches, summarising, and reporting the results}

When multiple reports described the same underlying approach, these reports were pooled in one approachcluster. The first report describing an approach and subsequent studies that validated or extended that approach were included. The name of the approach, citations to the initial report and/or common authorships were used to cluster the reports. The grading table was completed for each cluster separately to provide a structure for the subsequent content analysis. In the last part of the grading table, under the heading "validation approach", all validation studies are described together. For every approach-cluster a key contribution for the audiological field was derived from the associated report(s). A key contribution is a finding or claim made by the author(s) significant for the approach in general, stated in either the conclusion or discussion of a report in accordance with their objective.

\section{Results}

A total of 64 reports were included in this study. Fifty-six of the 64 reports were included according to the inclusion- and exclusion criteria, and eight reports were added to the approach-clusters. After clustering identical approaches, 27 approach-clusters remained including two that used machine learning. Extracted data items and grading of results on approaches are provided in the supplemental material, Table 3. 


\section{Accuracy and Validity of Automated Approaches}

Specifications of the reported accuracy and validity are described in Table 1. The accuracy is represented as a comparison against the gold standard and test-retest reliability. Twenty-two approaches were validated on normal-hearing and hearing-impaired people. Four studies were performed using normal-hearing subjects. ${ }^{25-27}$ One approach-cluster was only validated in a hearing-impaired population, using hearing aids as transducers. ${ }^{28}$ Automated audiometry was applied across a range of populations. All approaches were applied to adults except for Patel et $\mathrm{al}^{29}$ who only included children in their study. Eight approaches were validated in children, including three approaches that designed a child-friendly user-interface. ${ }^{29-31}$ Other test populations were elderly, ${ }^{32}$ veterans,${ }^{33}$ and persons exposed to occupational noise $e^{34}$ or ototoxic substances. ${ }^{35}$ Automated audiometry has also been applied as an alternative in low-resource environments for traditional manual audiometry. ${ }^{36-38}$ The userinterface plays an important role in making self-testing feasible in all populations and may require an iterative design process (including clinical pilot-studies)..$^{37,39}$

Table 1. Review of the validation, accuracy, and test population for automated and machine learning audiometry approaches $2012-2021$.

\begin{tabular}{|c|c|c|}
\hline Validity & & Descriptions of clustered approaches \\
\hline Accuracy & $\begin{array}{l}\text { comparison } \\
\text { against } \\
\text { conventional } \\
\text { audiometry }\end{array}$ & $\begin{array}{l}\text { Air conduction ( } n=23 \text { approach-clusters): } \\
4 \mathrm{RMSD}<6 \mathrm{~dB} \\
7 \mathrm{RMSD}<10 \mathrm{~dB} \\
9 \text { statistical equivalence } \\
3 \text { no statistical equivalence }\end{array}$ \\
\hline & & $\begin{array}{l}\text { Bone conduction ( } n=1 \text { approach-cluster) } \\
1 \text { statistical equivalence }\end{array}$ \\
\hline & & $\begin{array}{l}\text { Both air and bone conduction ( } n=3 \text { approach-clusters) } \\
2 \mathrm{RMSD}<6 \mathrm{~dB} \text { compared for air-conduction } \\
1 \mathrm{RMSD}<10 \mathrm{~dB} \text { compared for air-conduction } \\
1 \mathrm{RMSD}<10 \mathrm{~dB} \text { compared for bone-conduction } \\
2 \text { statistical equivalence for bone-conduction }\end{array}$ \\
\hline & Test-retest & $\begin{array}{l}\text { Air conduction ( } n=23 \text { approach-clusters): } \\
4 \mathrm{RMSD}<6 \mathrm{~dB} \\
1 \mathrm{RMSD}<10 \mathrm{~dB} \\
9 \text { statistical equivalence } \\
9 \text { test-retest not reported }\end{array}$ \\
\hline & & $\begin{array}{l}\text { Bone conduction ( } n=1 \text { approach-cluster) } \\
1 \text { test-retest not reported }\end{array}$ \\
\hline & & $\begin{array}{l}\text { Both air and bone conduction ( } n=3 \text { approach-clusters) } \\
1 \mathrm{RMSD}<6 \mathrm{~dB} \text { compared for air-conduction } \\
2 \mathrm{RMSD}<10 \mathrm{~dB} \text { compared for air-conduction } \\
1 \mathrm{RMSD}<6 \mathrm{~dB} \text { for bone-conduction } \\
2 \text { test-retest not reported }\end{array}$ \\
\hline Validation & orts) & $\begin{array}{l}49 \text { against the gold standard } \\
14 \text { against the reasonable standard } \\
1 \text { proof of concept }\end{array}$ \\
\hline & & 26 normal hearing \\
\hline
\end{tabular}


Test population $(n=27$ approachclusters):
23 tested hearing impaired

23 tested adults

8 tested children

\section{Test parameters and specifications}

Tests were all self-administered from the point the test starts. Four approaches had the option to switch to a manual audiometry mode. Table 2 summarises an overview of test parameters and specifications of the 27 approach-clusters, and Table 3 highlights key contributions. Most of the approaches used adaptive procedures that rely on the previous response only (here referred to as partially adaptive procedures). The most common example was the (modified) Hughson-Westlake staircase procedure $(n=20)$, which is based on the classical method of limits. ${ }^{40}$ Other partially adaptive procedures applied the method of adjustment, such as the Bekesy tracking method ${ }^{41}$ or the 'coarse-to-fine focus' algorithm. ${ }^{28}$ There was a single report of an approach that did not define the threshold seeking method, but had a built in protocol to alternate between ears during testing. ${ }^{42}$ Fully adaptive procedures, in contrast, use the complete set of all previous responses. Examples include Bayesian active learning procedures (also referred to as machine learning audiometry; $n=2)^{18,20}$ and maximum likelihood estimation $(n=2) \cdot{ }^{27,43}$

Most of the approaches used conventional calibration (20/27) according to ISO-standards. Six approaches used an unconventional calibration technique. Patel et al. ${ }^{29}$ determined a reference equivalent threshold level (RETSPL) for air conduction for the specific phone-headphone combination using manual audiometry as a reference. Masalski et al. ${ }^{44}$ used reference levels for calibration for smartphone and transducer combinations, collected in uncontrolled conditions in normal-hearing persons. Other calibration techniques were setting the volume of the device to $50 \%,{ }^{45}$ comparing and adjusting the output level to the input using a sound level meter $^{26,46}$ or using Thévenin-equivalent probe calibration. ${ }^{41}$

Table 2. Review of test parameters and specifications for automated audiometry approaches $2012-2021$.

\begin{tabular}{|l|l|}
\hline $\begin{array}{l}\text { Test parameters \& } \\
\text { specifications }\end{array}$ & Descriptions of approach clusters $(\mathbf{n}=\mathbf{2 7})$ \\
\hline Threshold seeking method & 20 (modified) Hughson-Westlake \\
$\begin{array}{l}\text { Underlying algorithm to } \\
\text { determine the thresholds }\end{array}$ & 2 machine learning \\
& 1 Bekesy tracking \\
& 4 other method \\
\hline Test range & 18 full frequency range $125-8000 \mathrm{~Hz}$ \\
Limits of the frequency and & 4 extended high frequencies $125-16000 \mathrm{~Hz}$ \\
intensity that can be tested & 5 reduced frequency range \\
\cline { 2 - 2 } & 14 Intensity range $0-100 \mathrm{~dB} \mathrm{HL}$ \\
& 10 reduced intensity range \\
& 3 intensity range not reported \\
\hline Masking & 9 automated masking \\
& 1 manual masking \\
\hline
\end{tabular}




\begin{tabular}{|l|l|}
\hline $\begin{array}{l}\text { Needed to prevent responses from } \\
\text { the non-test ear and obtain the } \\
\text { true threshold of the test ear }\end{array}$ & $\begin{array}{l}13 \text { no masking } \\
4 \text { masking not reported }\end{array}$ \\
\hline $\begin{array}{l}\text { Response method } \\
\text { Method of recording subject's } \\
\text { responses to test stimuli }\end{array}$ & $\begin{array}{l}9 \text { forced-choice } \\
12 \text { single response } \\
4 \text { forced-choice and single response } \\
2 \text { not reported }\end{array}$ \\
\hline $\begin{array}{l}\text { Transducers } \\
\text { Method of presenting stimuli, e.g. } \\
\text { insert phone or supra or } \\
\text { circumaural headphone }\end{array}$ & $\begin{array}{l}23 \text { air conduction transducers } \\
\text { Cand bone conduction transducers }\end{array}$ \\
\hline $\begin{array}{l}\text { Calibration } \\
\text { Unconventional calibration } \\
\text { methods are explained in the text }\end{array}$ & 20 conventional calibration \\
\hline $\begin{array}{l}\text { Digital devices } \\
\text { Reported Hardware needed to run } r \text { calibration not reported } \\
\text { the test. }\end{array}$ & 2 portable audiometer \\
& 9 computer-based \\
\hline $\begin{array}{l}\text { Quality control measures } \\
\text { Indicators of the reliability of the } \\
\text { test }\end{array}$ & 15 smartphone- or tablet-based \\
\hline
\end{tabular}

Table 3: key contributions of the automated and machine learning approaches to the audiological field; ${ }^{\text {a }}$ smartphone-based hearing test application, not yet commercialized; ${ }^{\mathbf{b}}$ automated hearing test commercialized by hearX $\mathrm{X}^{\mathrm{TM}}$ group.

\begin{tabular}{|c|c|}
\hline $\begin{array}{l}\text { Approach-Cluster (first author, } \\
\text { year, publications, approach name) }\end{array}$ & Key contribution(s) to the field \\
\hline Bean et al, $2021^{47}$ OtoKiosk & $\begin{array}{l}\text { It has the potential to be used in test environments like exam rooms as a clinical } \\
\text { tool for identifying hearing loss via air conduction separating persons with normal } \\
\text { and impaired hearing }\end{array}$ \\
\hline Chen et al, $2019^{28}$ & $\begin{array}{l}\text { A demo smartphone-based hearing self-assessment (SHSA) that runs on a hearing } \\
\text { aid which has statistical equivalence to manual audiometry }\end{array}$ \\
\hline Colsman et al, $2020^{25}$ & $\begin{array}{l}\text { Portable devices that use calibrated headphones result in much higher accuracies } \\
\text { than the uncalibrated devices. }\end{array}$ \\
\hline Corry et al, $2017^{26}$ & $\begin{array}{l}\text { The reliability of audiometer apps should not be assumed. Issues of accuracy and } \\
\text { calibration of consumer headphones need to be addressed before such } \\
\text { combinations can be used with confidence. }\end{array}$ \\
\hline Dewyer et al, $2019^{48}$ Earbone & A proof of concept for smartphone-based bone conduction threshold testing \\
\hline Foulad et al, $2013^{36,46,49}$ Eartrumpet & $\begin{array}{l}\text { An iOS-based software application for automated pure-tone hearing testing } \\
\text { without need for additional specialized equipment, yields hearing test results that } \\
\text { approach those of conventional audiometry }\end{array}$ \\
\hline Jacobs et al, $2012^{35,50}$ Oto-ID & $\begin{array}{l}\text { Automated (remote) hearing tests can provide clinicians information for } \\
\text { ototoxicity monitoring }\end{array}$ \\
\hline $\begin{array}{l}\text { Kung et al, } 2021^{31} \text { Kids Hearing } \\
\text { Game }\end{array}$ & $\begin{array}{l}\text { Tablet based audiometry using game-design elements can be used to test and } \\
\text { screen for hearing loss in children who may not have adequate access to resources } \\
\text { for traditional hearing screening }\end{array}$ \\
\hline Liu et al, $2015^{51}$ & $\begin{array}{l}\text { An interactive hearing self-testing system, consisting of a notebook computer, } \\
\text { sound card, and insert earphones is a valid, portable and sensitive instrument for } \\
\text { hearing thresholds self-assessment }\end{array}$ \\
\hline Manganella et al, $2018^{42}$ & $\begin{array}{l}\text { If the application detects increased levels of ambient noise, it is programmed to } \\
\text { stop the testing. }\end{array}$ \\
\hline Margolis et al, $2007^{23,52-55}$ AMTAS & $\begin{array}{l}\text { Fits in the clinical care pathway and incorporates a quality assessment method } \\
\left(\text { QUALIND }^{\circledR}\right) \text { that predicts the accuracy of the test }\end{array}$ \\
\hline
\end{tabular}




\begin{tabular}{|c|c|}
\hline $\begin{array}{l}\text { Margolis et al, } 2016^{33,56,57} \text { Home } \\
\text { Hearing Test }\end{array}$ & $\begin{array}{l}\text { It is developed and well suited to provide increased access to hearing testing and } \\
\text { support home telehealth programs. }\end{array}$ \\
\hline Masalski \& Kręcicki, 2013 $3^{44,58,59}$ & $\begin{array}{l}\text { This automated method uses smartphone model-specific reference sound levels } \\
\text { for calibration in the app. These biological reference sound levels have been } \\
\text { collected in uncontrolled conditions in normal-hearing persons. }\end{array}$ \\
\hline Meinke et al, 2017 $7^{60,61}$ WHATS & $\begin{array}{l}\text { Comparable performance is obtained with a mobile wireless automated hearing- } \\
\text { test system in occupational audiometry and obtaining hearing thresholds in } \\
\text { diverse test locations without the use of a sound booth }\end{array}$ \\
\hline Patel et al, $2021^{29}$ HearTest $^{\mathbf{a}}$ & $\begin{array}{l}\text { A novel subjective test-based approach was used to calibrate a smartphone- } \\
\text { earphone combination with respect to the reference audiometer }\end{array}$ \\
\hline Poling et al, $2016^{41}$ & $\begin{array}{l}\text { Specific tracking patterns are identifiable in subjects who experienced difficulty } \\
\text { converging to a reliable threshold. This behavioral information can be used to } \\
\text { develop algorithms that detect loss of engagement or lack of attention and create a } \\
\text { warning system to draw the listener back to the task. }\end{array}$ \\
\hline Schlittenlacher et al, $2018^{20}$ & $\begin{array}{l}\text { Bayesian active-learning methods provide an accurate estimate of hearing } \\
\text { thresholds in a continuous range of frequencies }\end{array}$ \\
\hline Schmidt et al, $2014^{43}$ & $\begin{array}{l}\text { A user-operated two-alternative forced-choice in combination with the method of } \\
\text { maximum likelihood does not require specific operating skills and the } \\
\text { repeatability is acceptable and similar to conventional audiometry }\end{array}$ \\
\hline Song et al, $2015^{18,62-64}$ MLAG & $\begin{array}{l}\text { Bayesian active-learning method determines the most informative next tone } \\
\text { leading to fast audiogram procedure and threshold estimation in a continuous } \\
\text { range of frequencies with potential to measure additional variables efficiently. }\end{array}$ \\
\hline Sun et al, $2019^{65}$ & Active noise control technology to measure outside the sound booth \\
\hline $\begin{array}{l}\text { Swanepoel et al, } 2010^{32,38,66-71} \\
\text { KUDUwave }\end{array}$ & $\begin{array}{l}\text { An automated portable diagnostic audiometer using improved passive attenuation } \\
\text { and real-time environmental noise monitoring making audiometry possible in } \\
\text { unconventional settings }\end{array}$ \\
\hline $\begin{array}{l}\text { Swanepoel et al, } 2014^{37,39,72-77} \\
\text { HearTest }^{\mathbf{b}}\end{array}$ & $\begin{array}{l}\text { A smartphone-based automated hearing test applicable in low resource } \\
\text { environments }\end{array}$ \\
\hline Szudek et al, 2012 $2^{45,78,79}$ Uhear & $\begin{array}{l}\text { uHear is applicable in the initial evaluation of patients with sudden sensorineural } \\
\text { hearing loss before a standard audiogram is available }\end{array}$ \\
\hline Van Tasell \& Folkeard, $2013^{80}$ & $\begin{array}{l}\text { Method of adjustment and the Hughson-Westlake method embedded in } \\
\text { automated audiometry can be considered equivalent in accuracy to conventional } \\
\text { audiometry }\end{array}$ \\
\hline Vinay et al, $2014^{27,34}$ NEWT & $\begin{array}{l}\text { The New Early Warning Test (NEWT), which is incorporated inside an active } \\
\text { communication earplug, serves as a reliable and efficient method to measure } \\
\text { auditory thresholds, especially in the presence of high background noise }\end{array}$ \\
\hline Whitton et al, $2016^{81}$ & $\begin{array}{l}\text { This study provides a proof of concept that several self-administered, automated } \\
\text { hearing measurements at home are statistically equivalent to conventional } \\
\text { audiometry in the clinic. }\end{array}$ \\
\hline Yeung et al, $2015^{30,82-86}$ Shoebox & $\begin{array}{l}\text { A method for threshold hearing assessments outside conventional sound booths } \\
\text { and with an interface suitable for children. }\end{array}$ \\
\hline
\end{tabular}

\section{Test efficiency}

No standard measure expressing test efficiency was reported across studies. The two machine learning approaches reported lower bounds of the test efficiency by comparing the number of required trials for the manual gold standard method and the machine learning method. Machine learning methods converged to a $5 \mathrm{~dB}$ precision for unmasked air conduction audiograms within 18 to 28 trials for one $\operatorname{side}^{20}$ or 19 to 44 trials bilaterally. ${ }^{63}$ The gold standard method required 93 to 114 trials on average, depending on the hearing loss configuration..$^{63}$ Heisey et al. ${ }^{63}$ also expressed the efficiency gains by comparing the total overall test time of $2 \cdot 1$ to $4 \cdot 8$ minutes for bilateral air conduction audiometry using the machine learning based procedure versus $6 \cdot 9$ to $9 \cdot 9$ minutes using the gold standard procedure. The two maximum likelihood approaches reported test time per 
ear ${ }^{27}$ or per frequency. ${ }^{43}$ Vinay et al. ${ }^{27}$ reported an average test time of $3 \cdot 0$ minutes for bilateral air conduction audiometry in $2 \mathrm{~dB}$ steps on an unconventional number of frequencies $(1,3,4,6 \mathrm{kHz})$ using a method based on maximum likelihood versus $5 \cdot 5$ minutes measured manually. However, this was achieved in normal-hearing persons for the purpose of monitoring occupational hearing health. Schmidt et al. ${ }^{43}$ aimed for high accuracy and reliability at the expense of efficiency, which is for example reflected in the requirement to have at least 30 responses before terminating the test and their use of a forced choice paradigm. They reported a test time of $2 \cdot 2$ minutes per frequency that could be reduced to $1 \cdot 0$ minute if only thresholds above $10 \mathrm{~dB} H \mathrm{HL}$ are relevant.

\section{Discussion}

In 2012 evidence for automated audiometry demonstrated similar reliability and accuracy as manual audiometry across limited reports especially for children and using bone conduction. ${ }^{21}$ In less than a decade, twenty-two novel approaches and developments across five existing approaches have appeared in 56 publications.

Promising new developments include machine learning techniques for more efficient hearing assessment $(n=2)$, use of tablets or smartphones as audiometer interface $(n=15)$, and child-friendly user-interfaces $(n=3)$ including game-design elements. The number of approaches that include bone conduction is still limited ( $\mathrm{n}=4)$, only two more than already existed in $2012 .{ }^{21}$

\section{Accuracy}

The required accuracy, reliability, and efficiency depend on the clinical aims and consequences. The ultimate aim for automated hearing assessment is to deliver clinical actionable estimates of hearing status (i.e. the clinician or patient acts appropriately for treatment given the diagnostic test results). In fully adaptive procedures, the level of precision and confidence needed to conclude the assessment can be set to any level by choosing the proper termination criteria, resulting in different trade-offs. Schmidt et al., ${ }^{43}$ for instance, aimed for high accuracy and reliability, whereas Heisey et al. ${ }^{63}$ aimed for high efficiency. Overall, several different measures were used to demonstrate accuracy across the identified reports. In our view, RMSD is the preferred indicator for accuracy with proven clinical relevance assuming, it has already been demonstrated that there is no bias between the automated and manually determined hearing thresholds (e.g. signed differences). In traditional clinical terms, automation is equal in accuracy to manual audiometry if the difference is within $6 \mathrm{~dB}$ RMSD. Six 
of the twenty-seven automated approaches meet this strict accuracy criterion. For many applications, however, the less strict $10 \mathrm{~dB}$ RMSD criterium is sufficient, which is achieved by seven additional automated approaches.

For bone conduction measurements, the accuracy is inherently lower than air conduction measurements due to conductor placement. ${ }^{23}$ However, this accuracy is typically sufficient to address the clinical question of whether conductive/mixed hearing loss is present and to choose and evaluate appropriate treatment. The feasibility of bone conduction assessments outside of a clinical setting (sound booth) remains difficult. Alternatively, this clinical question can be addressed with other tests, including tympanometry, otoscopy, or a combination of air conduction thresholds for tone and speech stimuli. ${ }^{87}$ At least 13 automated techniques have accuracy comparable to traditional manual air conduction audiometry as expressed in RMSD. Eighteen of the twentyseven approaches did not report on test-retest accuracy or used a measure of statistical equivalence that does not allow us to assess the accuracy.

One limit to the impact of achieved test accuracy is the high variation in the interpretation of audiograms by clinicians, regardless if those audiograms are determined using an automated or manual approach ${ }^{88}$ Automation can assist clinicians and patients to interpret the measurement by data-driven automated reporting of accuracy and reliability (including signalling for suspicious outcomes) such as QUALIND ${ }^{\circledR 53}$ or by automated classification for diagnostic purposes (including type and degree of hearing loss). Examples of automated classification include AMCLASS,${ }^{89}$ Autoaudio, ${ }^{90}$ and data-driven audiogram classification. ${ }^{91}$

\section{Reliability}

Reliability is based on representative validation, which means that the approach is demonstrated in the prospective population in an operational environment. Twenty-three approaches have been validated in a hearing-impaired population and eight studies tested in children. Other examples of validation in hard-to-test populations were not found. Further advances in automated audiometry that increase reliability included procedures to identify invalid responses $(n=5)$, monitoring environmental noise $(n=6)$, and do both $(n=7)$ to warn for invalid test conditions, making these tests applicable in more populations and environments. The digital devices, including smartphones and tablets, lend themselves to quality control measures for increased reliability with the host of integrated sensors 


\section{Efficiency}

A fair indicator of efficiency is the overall time required to conduct a test. Most approaches $(n=20)$ use the modified Hughson-Westlake procedure, which would have a similar test duration as manual audiometry. Maximum likelihood procedures demonstrated a 45\% reduction in test time in normal hearing persons. ${ }^{27}$ Machine learning based automated procedures have demonstrated a 70\% reduction in test time compared to manual audiometry for air conduction audiograms both in normal and hearing impaired persons. ${ }^{63}$ No machine learning approaches have incorporated bone conduction yet. Therefore, efficiency gains compared to full audiogram procedures are not available but are expected to yield similar efficiency gains. Another indicator for test efficiency is the number of stimuli required to reach the desired accuracy. This indicator is helpful to optimise the threshold seeking part of the approach. Reporting the equivalent time gains is recommended since this can be readily compared to other efficiency gains, including the reduced travelling time if a visit to the outpatient clinic can be replaced for an at-home test, or time savings by automating other parts of the clinical care pathway such as interpretation of the outcome.

\section{Future developments required}

To get an overall indicator of the technical maturity of an approach, developers are encouraged to use the technology readiness level (TRL) to report the development phase of a technology. Technology readiness levels were initially developed in aerospace to estimate the maturity of technology from basic concept to flight-proven product. ${ }^{92}$ To apply the TRL to automated audiometry would require an adjustment of the definition of TRL by the European Union to fit the hearing healthcare sector better. For those approaches that are ready for operational use, certification (e.g. CE and FDA) can further stimulate clinical adoption and iterative improvements based on clinical feedback. In addition, standards and consensus on what meta-data are needed in health applications to describe the test conditions and facilitate interpretation are currently missing.

\section{Limitations}

This scoping review included peer-reviewed reports taken from widely used and recognised scientific databases. A potential limitation is that some of the commercialised automated approaches may have been developed without peer-reviewed reports. Some automated approaches could therefore be more mature than reported. 
There is no gold standard for reporting audiometry validation studies, which limits a consistent comparison among approaches. Lastly, automated procedures may well be embraced by early adopters first, which could lead to projections on suitability that are overly optimistic for users with poorer digital proficiency.

\section{Conclusion and recommendations}

Since 2012 an increasing number of automated audiometry approaches have similar accuracy and validity as conventional manual audiometry. New developments offer features, versatility, and cost-effectiveness beyond manual audiometry. Fully adaptive procedures, including machine learning techniques, seek hearing thresholds more efficiently. Inexpensive devices such as smartphones can be turned into audiometers, increasing accessibility and availability. Higher reliability is achievable by signalling invalid test conditions, and childfriendly user-interfaces offer a solution to the hard to test population. These approaches can be implemented in the clinical care pathway, remote hearing healthcare, community-based services, and occupational healthcare to address the global need for accessible hearing loss diagnosis.

For successful adoption, standardised measures of accuracy, reliability and efficiency are needed for comparative purposes (including certification) and to gain the trust of prospective users. Further reliability can be achieved by determining which difficult to test populations may not be appropriate for automated testing and how to detect and then triage these patients to specialised centres. More user-friendly and failsafe procedures that include remote surveillance and quality control can support automated hearing assessment at-scale in specific populations and in concert with diagnostic assessments in other medical domains. Further contextual information, e.g. standardised meta-data, is needed to help clinicians interpret test outcomes' context and limitations. If researchers and clinicians deal carefully with its limitations, automated hearing assessments can be designed such that it forms an effective part of service delivery for many people who have or are at risk of hearing loss. Automated audiometry can be part of existing care pathways but also enable new service models, including task-shifting to community health workers delivering decentralized care and over-the counter or direct-to-consumer hearing aid dispensing. 


\section{Authors' contributions}

LP and JWW made equal contributions and share first authorship. LP, JWW and DWS conceptualised the study.

LP and JWW conducted the abstract screening. LP and JWW independently extracted the information directly

relevant to the scoping review question. All authors contributed to the data interpretation. LP and JWW took the lead in drafting the manuscript. RHE and DWS provided supervision, reviewed the results, and edited the manuscript.

\section{Declaration of interests}

DWS has a relationship with the hear $\mathrm{X}^{\mathrm{TM}}$ Group (Pty) Ltd, which includes equity, consulting, and potential royalties. DWS holds a patent for Smartphone based audiometry, as inventor.

\section{References}

1 Haile LM, Kamenov K, Briant PS, et al. Hearing loss prevalence and years lived with disability, 1990-2019: findings from the Global Burden of Disease Study 2019. The Lancet 2021; 397: 996-1009.

2 World Health Organization. World report on hearing. World Health Organization, $2021 \mathrm{https}$ //www.who.int/publications-detail-redirect/world-report-on-hearing (accessed April 1, 2021).

3 Kamenov K, Martinez R, Kunjumen T, Chadha S. Ear and Hearing Care Workforce: Current Status and its Implications. Ear Hear 2021; 42: $249-57$.

4 Wasmann J-WA, Lanting CP, Huinck WJ, et al. Computational Audiology: New Approaches to Advance Hearing Health Care in the Digital Age. Ear Hear 2021; Publish Ahead of Print. DOI:10.1097/AUD.0000000000001041.

$5 \quad$ Swanepoel DW, De Sousa KC, Smits C, Moore DR. Mobile applications to detect hearing impairment: opportunities and challenges. Bull World Health Organ 2019; 97: 7178.

6 World Economic Forum. Diagnostics for Better Health: Considerations for Global Implementation. World Economic Forum, 2021.

7 Bloem BR, Marks WJ, Silva de Lima AL, et al. The Personalized Parkinson Project: examining disease progression through broad biomarkers in early Parkinson's disease. $B M C$ Neurol 2019; 19: 160.

8 Gatsios D, Antonini A, Gentile G, et al. Mhealth for remote monitoring and management of Parkinson's disease: determinants of compliance and validation of a tremor evaluation method. JMIR MHealth UHealth 2020. https://epubs.surrey.ac.uk/856376/ (accessed April 12, 2021).

9 Philipsen RHHM, Sánchez CI, Melendez J, Lew WJ, van Ginneken B. Automated chest X-ray reading for tuberculosis in the Philippines to improve case detection: a cohort study. Int J Tuberc Lung Dis Off J Int Union Tuberc Lung Dis 2019; 23: 805-10.

10 Wilson BS, Tucci DL, Merson MH, O’Donoghue GM. Global hearing health care: new findings and perspectives. The Lancet 2017; 390: 2503-15. 
11 McDaid D, Park A-L, Chadha S. Estimating the global costs of hearing loss. Int $J$ Audiol 2021; 60: 162-70.

12 Tsimpida D, Kontopantelis E, Ashcroft DM, Panagioti M. Conceptual Model of Hearing Health Inequalities (HHI Model): A Critical Interpretive Synthesis. Trends Hear 2021; 25: 23312165211002964.

13 Livingston G, Sommerlad A, Orgeta V, et al. Dementia prevention, intervention, and care. The Lancet 2017; 390: 2673-734.

14 Manchaiah V, Eikelboom RH, Bennett RJ, Swanepoel DW. International survey of audiologists during the COVID-19 pandemic: effects on the workplace. Int J Audiol 2021; : $1-8$.

15 Saunders GH, Roughley A. Audiology in the time of COVID-19: practices and opinions of audiologists in the UK. Int J Audiol 2021; 60: 255-62.

16 Eksteen S, Launer S, Kuper H, Eikelboom RH, Bastawrous A, Swanepoel DW. Hearing and vision screening for preschool children using mobile technology, South Africa. Bull World Health Organ 2019; 97: 672-80.

17 Békésy G v. A new audiometer. Acta Otolaryngol (Stockh) 1947; 35: 411-22.

18 Barbour DL, Howard RT, Song XD, et al. Online Machine Learning Audiometry. Ear Hear 2019; 40: 918-26.

19 Gardner JR, Malkomes G, Garnett R, Weinberger KQ, Barbour DL, Cunningham J. Bayesian Active Model Selection with an Application to Automated Audiometry. In: NIPS. 2015.

20 Schlittenlacher J, Turner RE, Moore BCJ. Audiogram estimation using Bayesian active learning. $J$ Acoust Soc Am 2018; 144: 421.

21 Mahomed F, Swanepoel DW, Eikelboom RH, Soer M. Validity of Automated

Threshold Audiometry: A Systematic Review and Meta-Analysis. Ear Hear 2013; 34: 74552.

22 Arksey H, O’Malley L. Scoping studies: towards a methodological framework. Int J Soc Res Methodol 2005; 8: 19-32.

23 Margolis RH, Glasberg BR, Creeke S, Moore BCJ. AMTAS: automated method for testing auditory sensitivity: validation studies. Int J Audiol 2010; 49: 185-94.

24 American Speech-Language-Hearing Association. Guidelines for manual pure-tone threshold audiometry. 2005. www.asha.org/policy.

25 Colsman A, Supp GG, Neumann J, Schneider TR. Evaluation of Accuracy and Reliability of a Mobile Screening Audiometer in Normal Hearing Adults. Front Psychol 2020; 11: 744.

26 Corry M, Sanders M, Searchfield GD. The accuracy and reliability of an app-based audiometer using consumer headphones: pure tone audiometry in a normal hearing group. Int J Audiol 2017; 56: 706-10.

27 Vinay, Svensson UP, Kvaløy O, Berg T. A comparison of test-retest variability and time efficiency of auditory thresholds measured with pure tone audiometry and new early warning test. Appl Acoust 2015; 90: 153-9.

28 Chen F, Wang S, Li J, Tan H, Jia W, Wang Z. Smartphone-Based Hearing SelfAssessment System Using Hearing Aids With Fast Audiometry Method. IEEE Trans Biomed Circuits Syst 2019; 13: 170-9.

29 Patel K, Thibodeau L, McCullough D, Freeman E, Panahi I. Development and Pilot Testing of Smartphone-Based Hearing Test Application. Int J Environ Res Public Health 2021; 18. DOI:10.3390/ijerph18115529.

30 Yeung JC, Heley S, Beauregard Y, Champagne S, Bromwich MA. Self-administered hearing loss screening using an interactive, tablet play audiometer with ear bud headphones. Int J Pediatr Otorhinolaryngol 2015; 79: 1248-52. 
31 Kung B, Kunda L, Groff S, Miele E, Loyd M, Carpenter DM. Validation Study of Kids Hearing Game: A Self-Administered Pediatric Audiology Application. Perm J 2021; 25. DOI:10.7812/TPP/20.157.

32 Maclennan-Smith F, Swanepoel DW, Hall JW. Validity of diagnostic pure-tone audiometry without a sound-treated environment in older adults. Int J Audiol 2013; 52: 6673.

33 Margolis RH, Killion MC, Bratt GW, Saly GL. Validation of the Home Hearing Test $^{\mathrm{TM}}$. J Am Acad Audiol 2016; 27: 416-20.

34 Vinay, Henriksen V, Kvaloy O, Svensson UP. Development and Calibration of a New Automated Method to Measure Air Conduction Auditory Thresholds Using an Active Earplug. Acta Acust United Acust 2014; 100: 113-7.

35 Jacobs PG, Silaski G, Wilmington D, et al. Development and Evaluation of a Portable Audiometer for High-Frequency Screening of Hearing Loss From Ototoxicity in Homes/Clinics. IEEE Trans Biomed Eng 2012; 59: 3097-103.

36 Kelly EA, Stadler ME, Nelson S, Runge CL, Friedl, D. R. Tablet-based Screening for Hearing Loss: Feasibility of Testing in Nonspecialty Locations. Otol Neurotol 2018; 39: 4106.

37 Sandström J, Swanepoel DW, Laurent C, Umefjord G, Lundberg T. Accuracy and Reliability of Smartphone Self-Test Audiometry in Community Clinics in Low Income Settings: A Comparative Study. Ann Otol Rhinol Laryngol 2020; 129: 578-84.

38 Visagie A, Swanepoel DW, Eikelboom RH. Accuracy of Remote Hearing Assessment in a Rural Community. Telemed E-Health 2015; 21: 930-7.

39 Sandström J, Swanepoel DW, Carel Myburgh H, Laurent C. Smartphone threshold audiometry in underserved primary health-care contexts. Int J Audiol 2016; 55: 232-8. 40 Gescheider GA. Psychophysics: The Fundamentals. Psychology Press, 2013.

41 Poling GL, Kunnel TJ, Dhar S. Comparing the Accuracy and Speed of Manual and Tracking Methods of Measuring Hearing Thresholds. Ear Hear 2016; 37: e336-40.

42 Manganella JL, Stiles DJ, Kawai K, Barrett DL, O’Brien LB, Kenna MA. Validation of a portable hearing assessment tool: Agilis Health Mobile Audiogram. Int J Pediatr Otorhinolaryngol 2018; 113: 94-8.

43 Schmidt JH, Brandt C, Pedersen ER, et al. A user-operated audiometry method based on the maximum likelihood principle and the two-alternative forced-choice paradigm. Int $J$ Audiol 2014; 53: 383-91.

44 Masalski M, Kipiński L, Grysiński T, Kręcicki T. Hearing tests on mobile devices: evaluation of the reference sound level by means of biological calibration. J Med Internet Res 2016; 18: e130.

45 Szudek J, Ostevik A, Dziegielewski P, et al. Can Uhear me now? Validation of an iPod-based hearing loss screening test. J Otolaryngol - Head Neck Surg J Oto-RhinoLaryngol Chir Cervico-Faciale 2012; 41 Suppl 1: S78-84.

46 Foulad A, Bui P, Djalilian H. Automated audiometry using apple iOS-based application technology. Otolaryngol Head Neck Surg 2013; 149: 700-6.

47 Bean BN, Roberts RA, Picou EM, Angley GP, Edwards AJ. Automated Audiometry in Quiet and Simulated Exam Room Noise for Listeners with Normal Hearing and Impaired Hearing. J Am Acad Audiol 2021; published online May 25. DOI:10.1055/s-0041-1728778. 48 Dewyer NA, Jiradejvong P, Lee DS, Kemmer JD, Henderson Sabes J, Limb CJ. Automated Smartphone Audiometry: A Preliminary Validation of a Bone-Conduction Threshold Test App. Ann Otol Rhinol Laryngol 2019; 128: 508-15.

49 Saliba J, Al-Reefi M, Carriere JS, Verma N, Provencal C, Rappaport JM. Accuracy of Mobile-Based Audiometry in the Evaluation of Hearing Loss in Quiet and Noisy Environments. Otolaryngol Neck Surg 2017; 156: 706-11. 
50 Dille MF, Jacobs PG, Gordon SY, Helt WJ, McMillan GP. OtoID: new extended frequency, portable audiometer for ototoxicity monitoring. J Rehabil Res Dev 2013; 50: $997-$ 1006.

51 Liu Y, Yang D, Xiong F, Yu L, Ji F, Wang QJ. Development and Validation of a Portable Hearing Self-Testing System Based on a Notebook Personal Computer. J Am Acad Audiol 2015; 26: 716-23.

52 Eikelboom RH, Swanepoel de W, Motakef S, Upson GS. Clinical validation of the AMTAS automated audiometer. Int J Audiol 2013; 52: 342-9.

53 Margolis RH, Saly GL, Le C, Laurence J. Qualind: A method for assessing the accuracy of automated tests. J Am Acad Audiol 2007; 18: 78-89.

54 Margolis RH, Moore BC. AMTAS $\AA$ : Automated method for testing auditory sensitivity: III. Sensorineural hearing loss and air-bone gaps. Int J Audiol 2011; 50: 440-7. 55 Margolis RH, Frisina R, Walton JP. AMTAS ${ }^{\circledR}$ : Automated method for testing auditory sensitivity: II. Air conduction audiograms in children and adults. Int J Audiol 2011; 50: 434-9.

56 Margolis RH, Bratt G, Feeney MP, Killion MC, Saly GL. Home Hearing Test: Within-Subjects Threshold Variability. Ear Hear 2018; 39: 906-9.

57 Mosley CL, Langley LM, Davis A, McMahon CM, Tremblay KL. Reliability of the Home Hearing Test: Implications for Public Health. J Am Acad Audiol 2019; 30: 208-16. 58 Masalski M, Kręcicki T. Self-test web-based pure-tone audiometry: validity evaluation and measurement error analysis. J Med Internet Res 2013; 15: e 71.

59 Masalski M, Grysiński T, Kręcicki T. Hearing tests based on biologically calibrated mobile devices: comparison with pure-tone audiometry. JMIR MHealth UHealth 2018; 6: e10.

60 Magro I, Clavier O, Mojica K, et al. Reliability of Tablet-based Hearing Testing in Nicaraguan Schoolchildren: A Detailed Analysis. Otol Neurotol 2020; 41: 299-307.

61 Meinke DK, Norris JA, Flynn BP, Clavier OH. Going wireless and booth-less for hearing testing in industry. Int $J$ Audiol 2017; 56: 41-51.

62 Song XD, Wallace BM, Gardner JR, Ledbetter NM, Weinberger KQ, Barbour DL. Fast, Continuous Audiogram Estimation Using Machine Learning. Ear Hear 2015; 36: e32635 .

63 Heisey KL, Walker AM, Xie K, Abrams JM, Barbour DL. Dynamically Masked Audiograms With Machine Learning Audiometry. Ear Hear 2020; 41(6): 1692-702. 64 Heisey KL, Buchbinder JM, Barbour DL. Concurrent Bilateral Audiometric Inference. Acta Acust United Acust 2018; 104: 762-5.

65 Sun C, Liu Y, Wang X. An Automated Hearing Test Equipment Based on Active Noise Control Technology. 2019: 1-5.

66 Brennan-Jones CG, Eikelboom RH, Swanepoel de W, Friedl, P. L., Atlas MD. Clinical validation of automated audiometry with continuous noise-monitoring in a clinically heterogeneous population outside a sound-treated environment. Int J Audiol 2016; 55: 50713.

67 Swanepoel DW, Mngemane S, Molemong S, Mkwanazi H, Tutshini S. Hearing Assessment-Reliability, Accuracy, and Efficiency of Automated Audiometry. Telemed EHealth 2010; 16: 557-63.

68 Swanepoel DW, Biagio L. Validity of Diagnostic Computer-Based Air and Forehead Bone Conduction Audiometry. J Occup Environ Hyg 2011; 8: 210-4.

69 Govender SM, Mars M. Validity of automated threshold audiometry in school aged children. Int J Pediatr Otorhinolaryngol 2018; 105: 97-102.

70 Storey KK, Muñoz K, Nelson L, Larsen J, White K. Ambient noise impact on accuracy of automated hearing assessment. Int J Audiol 2014; 53: 730-6. 
71 Swanepoel de W, Matthysen C, Eikelboom RH, Clark JL, Hall JW 3rd. Pure-tone audiometry outside a sound booth using earphone attentuation, integrated noise monitoring, and automation. Int J Audiol 2015; 54: 777-85.

72 Bornman M, Swanepoel DW, De Jager LB, Eikelboom RH. Extended high-frequency smartphone audiometry: validity and reliability. $J$ Am Acad Audiol 2019; 30: 217-26.

73 Swanepoel DW, Myburgh HC, Howe DM, Mahomed F, Eikelboom RH. Smartphone hearing screening with integrated quality control and data management. Int J Audiol 2014; 53: 841-9.

74 Brittz M, Heinze B, Mahomed-Asmail F, Swanepoel DW, Stoltz A. Monitoring Hearing in an Infectious Disease Clinic with mHealth Technologies. J Am Acad Audiol 2019; 30: 482-92.

75 Corona AP, Ferrite S, Bright T, Polack S. Validity of hearing screening using hearTest smartphone-based audiometry: performance evaluation of different response modes. Int $J$ Audiol 2020; 59: 666-73.

76 Rodrigues LC, Ferrite S, Corona AP. Validity of hearTest Smartphone-Based Audiometry for Hearing Screening in Workers Exposed to Noise. J Am Acad Audiol 2020; published online Dec 9. DOI:10.1055/s-0040-1718931.

77 van Tonder J, Swanepoel W, Mahomed-Asmail F, Myburgh H, Eikelboom RH. Automated Smartphone Threshold Audiometry: Validity and Time Efficiency. J Am Acad Audiol 2017; 28: 200-8.

78 Handzel O, Ben-Ari O, Damian D, Priel MM, Cohen J, Himmelfarb M. SmartphoneBased Hearing Test as an Aid in the Initial Evaluation of Unilateral Sudden Sensorineural Hearing Loss. Audiol Neurotol 2013; 18: 201-7.

79 Khoza-Shangase K, Kassner L. Automated screening audiometry in the digital age: exploring uhear ${ }^{\mathrm{TM}}$ and its use in a resource-stricken developing country. Int J Technol Assess Health Care 2013; 29: 42-7.

80 Van Tasell DJ, Folkeard P. Reliability and accuracy of a method of adjustment for self-measurement of auditory thresholds. Otol Neurotol 2013; 34: 9-15.

81 Whitton JP, Hancock KE, Shannon JM, Polley DB. Validation of a Self-Administered Audiometry Application: An Equivalence Study. Laryngoscope 2016; 126: 2382-8.

82 Yeung J, Javidnia H, Heley S, Beauregard Y, Champagne S, Bromwich M. The new age of play audiometry: prospective validation testing of an iPad-based play audiometer. $J$ Otolaryngol Head Neck Surg 2013; 42: 21.

83 Thompson GP, Sladen DP, Borst BJH, Still OL. Accuracy of a Tablet Audiometer for Measuring Behavioral Hearing Thresholds in a Clinical Population. Otolaryngol--Head Neck Surg Off J Am Acad Otolaryngol-Head Neck Surg 2015; 153: 838-42.

84 Bastianelli M, Mark AE, McAfee A, Schramm D, Lefrançois R, Bromwich M. Adult validation of a self-administered tablet audiometer. J Otolaryngol - Head Neck Surg 2019; 48: 59.

85 Vijayasingam A, Frost E, Wilkins J, et al. Tablet and web-based audiometry to screen for hearing loss in adults with cystic fibrosis. Thorax 2020; 75: 632-9.

86 Yalamanchali S, Albert RR, Staecker H, Nallani R, Naina P, J Sykes K. Evaluation of Portable Tablet-Based Audiometry in a South Indian Population. Indian J Otolaryngol Head Neck Surg 2020; published online Sept 2. DOI:10.1007/s12070-020-02094-3.

87 De Sousa KC, Swanepoel DW, Moore DR, Myburgh HC, Smits C. Improving Sensitivity of the Digits-In-Noise Test Using Antiphasic Stimuli. Ear Hear 2020; 41: 442-50. 88 Brennan-Jones CG, Eikelboom RH, Bennett RJ, Tao KF, Swanepoel DW. Asynchronous interpretation of manual and automated audiometry: Agreement and reliability. $J$ Telemed Telecare 2018; 24: 37-43.

89 Margolis RH, Saly GL. Asymmetric hearing loss: definition, validation, and 
prevalence. Otol Neurotol 2008; 29: 422-31.

90 Crowson MG, Lee JW, Hamour A, et al. AutoAudio: Deep Learning for Automatic Audiogram Interpretation. J Med Syst 2020; 44: 163.

91 Charih F, Bromwich M, Mark AE, Lefrançois R, Green JR. Data-Driven Audiogram Classification for Mobile Audiometry. Sci Rep 2020; 10: 3962.

92 Héder M. From NASA to EU: the evolution of the TRL scale in Public Sector Innovation. Innov $J$ 2017; 22: 1-23. 